[2] Verazza, et al. Disease status, reasons for discontinuation and adverse events in 1038 Italian children with juvenile idiopathic arthritis treated with etanercept. PROJ 2016

Disclosure of Interests: Maria Francesca Gicchino: None declared, Gabriella Giancane: None declared, Alessandra Alongi: None declared, Silvia Rosina: None declared, Jessica Tibaldi: None declared, Marta Mazzoni: None declared, Angelo Ravelli Grant/research support from: Angelini, AbbVie, Bristol-Myers Squibb, Johnson \& Johnson, Novartis, Pfizer, Reckitt Benkiser, and Roche, Consultant for: Angelini, AbbVie, Bristol-Myers Squibb, Johnson \& Johnson, Novartis, Pfizer, Reckitt Benkiser, and Roche, Speakers bureau: Angelini, AbbVie, Bristol-Myers Squibb, Johnson \& Johnson, Novartis, Pfizer, Reckitt Benkiser, and Roche, Alessandro Consolaro Grant/research support from: AbbVie, Pfizer,

DOI: 10.1136/annrheumdis-2019-eular.7784

\section{SAT0502 EFFICACY AND SAFETY OF ADALIMUMAB IN JUVENILE IDIOPATHIC ARTHRITIS - 10 YEAR EXPERIENCE USING DATA OF THE BIKER REGISTRY}

Gerd Horneff $^{1,2}$, Kisten Minden ${ }^{1}$, Toni Hospach ${ }^{1}$, Ivan Foeldvari ${ }^{1}$, Peter Haas ${ }^{1}$, Angelika Thon ${ }^{1}$, Betina Rogalski ${ }^{1}$, Gerd Ganser ${ }^{1}$, Frank Weller-Heinemann ${ }^{1}$, Andreas Urban ${ }^{1}$, Markus Hufnagel ${ }^{1}$, Prasad Oommen ${ }^{1}$, Ariane Klein ${ }^{1} .{ }^{1}$ BIKERRegistry, Sankt Augustin, Germany; ${ }^{2}$ Paediatric Rheumatology Centre, General Paediatrics, Sankt Augustin, Germany

Background: Since 2008, Adalimumab is approved for polyarticular juvenile idiopathic arthritis (JIA) and approval has been extended to other JIA categories and for uveitis.

Objectives: To evaluate efficacy and safety of Adalimumab in clinical practice in JIA patients in comparison to a biologic-naïve JIA cohort using the German Biologics registry (BiKeR).

Methods: Baseline demographics and disease activity parameters have been documented. Efficacy was determined using the JADAS10. Safety assessments were based on adverse events (AE) reports processed according to MedDRA.

Results: Until October 1, 2018, 951 JIA patients treated with Adalimumab were registered in BiKeR, representing 1519 patient-years (PY) of exposure. The total observation time (from date of first dose until last followup, censored, if another biologic was started) was calculated with 1709 PY.

At baseline, the cohort treated with Adalimumab had experienced disease with a disease duration of $5.4+/-3.9$ years (mean+/-SD). 849 patients (89.3\%) were pretreated with methotrexate, 525 (54.2\%) with Etanercept. Concomitantly, $584(61.4 \%)$ received methotrexate, 529 (55.6\%) NSAIDs and $255(26.8 \%)$ systemic corticosteroids. In the control cohort, 1517 biologic naive JIA patients started methotrexate.

Upon treatment, the median (IQR1-3) JADAS10 score decreased from 9.8 (4.7-15.5) at baseline to $3.9(0.9-9.7)$ at the last follow-up. With respect to patients with ongoing treatment, approximately $43 \%$ achieved a JADAS defined minimal disease activity while $25 \%$ reached a JADAS defined remission at last follow-up.

$904 \mathrm{AE}$ have been observed during exposure or up to 90 days follow-up (58.4/100 exposure years (EY) [95\% Cl 54.7-62.3]). 66 qualified as serious $A E$ (SAE) (4.3/100 EY [3.3-5.4]). These figures were compared to $1294 \mathrm{AE}$ reported in the control cohort (34.8/year [32.9-36.8]) and 52 SAE (1.4/100 EY [1.1-1.8]).

Adverse events of special interest were serious/medically important infection $(n=33)$, opportunistic infection $(n=6$, all H. zoster), malignancy $(n=2)$, anaphylaxis/hypersensitivities $(n=3)$, thrombotic disorders $(n=2)$, autoimmune diseases $(n=91$, including 12 cases with psoriasis and 53 reports of uveitis), bleeding $(n=3)$, cytopenias $(n=4)$, pregnancies $(n=2)$. Macrophage activation syndrome, demyelination, cardiac or cerebral infarction, or death were not observed. However, 2 malignancies were reported in patients who had ever been exposed to Adalimumab before. Both events were judged as unrelated.

A total of 449 patients (48.5\%) discontinued Adalimumab, 188 (19.8\%) due to lack of efficacy, $111(11.7 \%)$ due to remission and $78(8.2 \%)$ because of intolerance.

Conclusion: The current analysis adds to the established safety profile of Adalimumab and demonstrates that the rate of SAEs was comparable and consistent with the overall $A E$ profile in paediatric patients. As expected, infections were the most frequent SAE. Uveitis, as well as psoriasis, are likely associated with JIA. Of notice, only one patient developed a chronic inflammatory bowel disease. No new safety signals specific to the paediatric population were identified in this large cohort of JIA patients.

\section{Efficacy measure: JADAS 10}
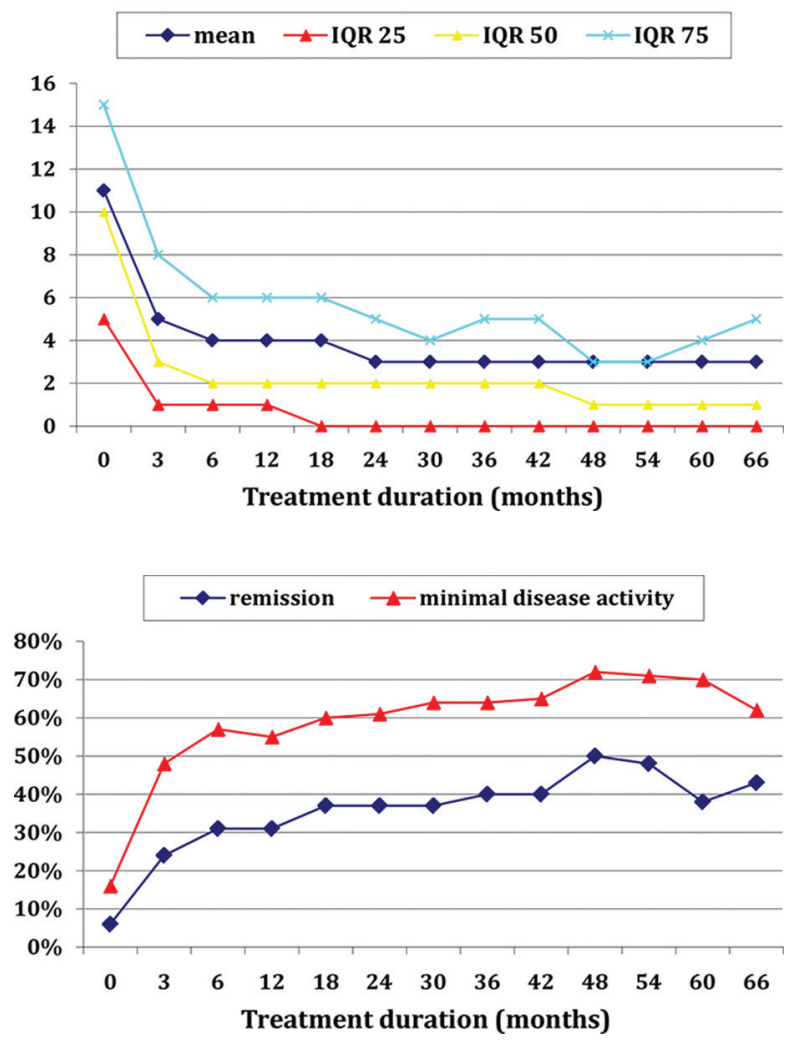

\section{REFERENCES}

[1] Klein A, Becker I, Minden K, Foeldvari I, Haas JP, Horneff G. Adalimumab versus adalimumab and methotrexate for the treatment of juvenile idiopathic arthritis: long-term data from the German BIKER registry. Scand $J$ Rheumatol. 2018 Nov 9:1-10.

Acknowledgement: The authors acknowledge all patients, parents and ciontributors to the BIKER registry and Abbvie, Germany, for financial Support for parts of BIKER.

Disclosure of Interests: Gerd Horneff: None declared, Kisten Minden Grant/research support from: Pfizer, Abbvie, Toni Hospach Speakers bureau: Chugai, Roche, Novartis, Ivan Foeldvari Consultant for: Chugai, Novartis, Peter Haas Grant/research support from: Pfizer, Angelika Thon None declared, Betina Rogalski <: None declared, Gerd Ganser: None declared, Frank Weller-Heinemann: None declared, Andreas Urban: None declared, Markus Hufnagel: None declared, Prasad Oommen: None declared, Ariane Klein: None declared DOI: 10.1136/annrheumdis-2019-eular.1457

\section{SAT0503 DEVELOPMENT OF MALIGNANCIES IN JIA PATIENTS EXPOSED TO BIOLOGIC AGENTS:A SINGLE CENTRE RETROSPECTIVE STUDY}

Oya Koker ${ }^{1}$, Sezgin Sahin ${ }^{1}$, Amra Adrovic ${ }^{1}$, Mehmet Yildiz $^{1}$, Kenan Barut $^{1}$, Rukiye Eker Omeroglu², Ozgur Kasapcopur'. 'Istanbul University-Cerrahpasa, Cerrahpasa Medical School, Pediatric Rheumatology, İstanbul, Turkey; ${ }^{2}$ stanbul University, Istanbul School of Medicne, Pediatric Rheumatology, Istanbul, Turkey

Background: Over the last two decades, the usage of biological agents in the treatment of Juvenile Idiopathic Arthritis (JIA) has been a successful and promising approach in controlling the disease activity and preventing chronic sequelaes. However, since Food and Drug Administration (FDA) has drawn attention to the possible association between the use of biological agents and the development of malignancy in 2008, there are ongoing concerns about the long-term safety data and side effect profile of the drugs with the contradictory study results.

Objectives: We aimed to present preliminary data on the incidence of malignancy in patients with JIA treated with biological agents versus the general population rates in Turkey. 